\title{
A comparison of short-term outcomes of laparoscopic-assisted total gastrectomy and open total gastrectomy in early gastric cancer
}

\author{
Ah-Rem Jeong, Ji-Hyeon Park, Jun-Young Yang, Woon-Kee Lee \\ Department of Surgery, Gachon University Gil Medical Center, Gachon University College of Medicine, Incheon, Korea
}

Purpose: This study aimed to compare the postoperative outcomes of open total gastrectomy (OTG) and laparoscopic-assisted total gastrectomy (LATG) and prove that postoperative outcomes of LATG can be improved through a surgeon's experience.

Methods: 62 patients who underwent OTG and 82 patients who underwent LATG were enrolled in this study. To objectively assess the postoperative outcomes, we decided to apply the Clavien-Dindo classification. This study was performed based on postoperative complications occurring within 30 days after total gastrectomy.

Results: There was no statistically significant difference between the two groups with regard to intraoperative transfusion $(P>0.99)$, overall postoperative complications $(P>0.99)$, and major postoperative complications $(P=0.731)$. Leakage of esophagojejunostomy was the most common complication after LATG. There is no statistically significant difference in the number of overall postoperative complications between the early LATG and late LATG groups $(P=0.349)$. However, there is significant difference in the number of major complications between the two groups $(P=0.026)$.

Conclusion: LATG is not inferior to OTG and improved by learning in terms of postoperative outcomes in this study.

Keywords: Total gastrectomy, Laparoscopy, Postoperative complication, Gastric cancer

\section{INTRODUCTION}

Globally, the incidence of gastric cancer is decreasing, but in Korea, gastric cancer has the highest incidence among all cancers. Moreover, although the incidence of gastric cancer in Korea is decreasing slightly [1], the incidence of early gastric cancer (EGC) is increasing annually. The reasons for this are the widespread use of high-quality endoscopy in medical institutions, increasing individual health screenings, and national cancer screening programs [2] .

In 1991, after laparoscopic-assisted gastrectomy was first introduced by Kitano, laparoscopic-assisted distal gastrectomy (LADG)

Received: Sep 4, 2017 Accepted: Nov 29, 2017

Correspondence to: Woon-Kee Lee

Department of Surgery, Gachon University Gil Medical Center, Gachon

University College of Medicine, 21 Namdong-daero 774beon-gil,

Namdong-gu, Incheon 21565, Korea

Tel: +82-32-460-3244, Fax: +82-32-460-3247

E-mail: Iwk@gilhospital.com

Copyright (C) Korean Society of Surgical Oncology

This is an Open Access article distributed under the terms of the Creative Commons Attribution Non-Commercial License (http://creativecommons.org/licenses/by-nc/4.0) which permits unrestricted non-commercial use, distribution, and reproduction in any medium, provided the original work is properly cited. began to spread widely [3]. LADG has been recognized for its surgical feasibility through several studies [4,5] and applied to the treatment of advanced gastric cancer as well as EGC [6]. Laparoscopic-assisted total gastrectomy (LATG) is more invasive than LADG [7,8]; therefore, a surgeon who has mastered LADG cannot easily perform LATG. The difficulty of esophagojejunostomy and lymph node dissection has also been a great barrier in the performance of LATG. Over the years, however, LATG has been recognized for its surgical feasibility and better postoperative outcomes compared to conventional open total gastrectomy (OTG) [9-12]. As a result, LATG cases are increasing annually.

As the incidence of EGC increases, postoperative outcomes of patients are expected to improve if appropriate treatment is performed. As mentioned, a minimally invasive surgery has several advantages in improving the postoperative outcomes of patients. Therefore, this study aimed to compare the postoperative outcomes of OTG and LATG and prove that postoperative outcomes of LATG can be improved through a surgeon's experience. 


\section{METHODS}

A total of 533 patients underwent total gastrectomy (TG) due to gastric cancer from January 2005 to July 2016 at Gachon University Gil Hospital, and all operations were performed by one surgeon. We adopted D2 lymphadenectomy without splenectomy as the standard procedure. Tumor, node and metastasis (TNM) classification is based on the American Joint Committee on Cancer (AJCC) 7 th edition. LADG and LATG were first performed in January 2005 and December 2010, respectively, in our hospital. After five years of experience with LADG, LATG was performed. We have started LATG in December 2010. LATG was performed when the depth of tumor confined to mucosa and submucosa and absence of lymph node metastases located in upper and middle gastric portion in preoperative evaluation [10]. Although diagnosed with EGC, there were 29 patients who underwent OTG from December 2010 to July 2016. They were diagnosed as clinically advanced gastric cancer (AGC) in the preoperative examination, but diagnosed as EGC in the final pathology report and these cases were included in our study.

Data were available for 533 patients who underwent TG including 422 who underwent OTG and 111 who underwent LATG. Pa- tients who underwent LATG due to a positive proximal resection margin and anastomosis site leakage after LADG and AGC confirmed by a pathology report were excluded from this study. Additionally, patients who underwent OTG because of recurrent remnant stomach cancer and patients who underwent a combined operation including TG due to a synchronous malignancy were also excluded. Finally, 62 patients who underwent OTG and 82 patients who underwent LATG were enrolled in this study (Fig. 1). Patients who underwent LATG were divided into two groups, which were compared in terms of postoperative outcomes to determine the effect of a surgeon's experience.

OTG was performed using the long upper midline incision from xiphoid process to supra-umbilical area at the supine position. Anastomosis method in all OTG was end to side anastomosis using anvil and circular stapler. And D2 lymph node dissection was performed. In LATG, the patient was placed in a lithotomy position. The surgeon stood on the right side of patient and first assistant stood on left side of patient. The scopist was positioned between the patient's legs. We used six trocars (Fig. 2). Epigastric port was used to insert liver retractor. Like OTG, D2 lymph node dissection was performed in LATG. We performed end-to-side anastomosis for approximately one year after the first LATG in

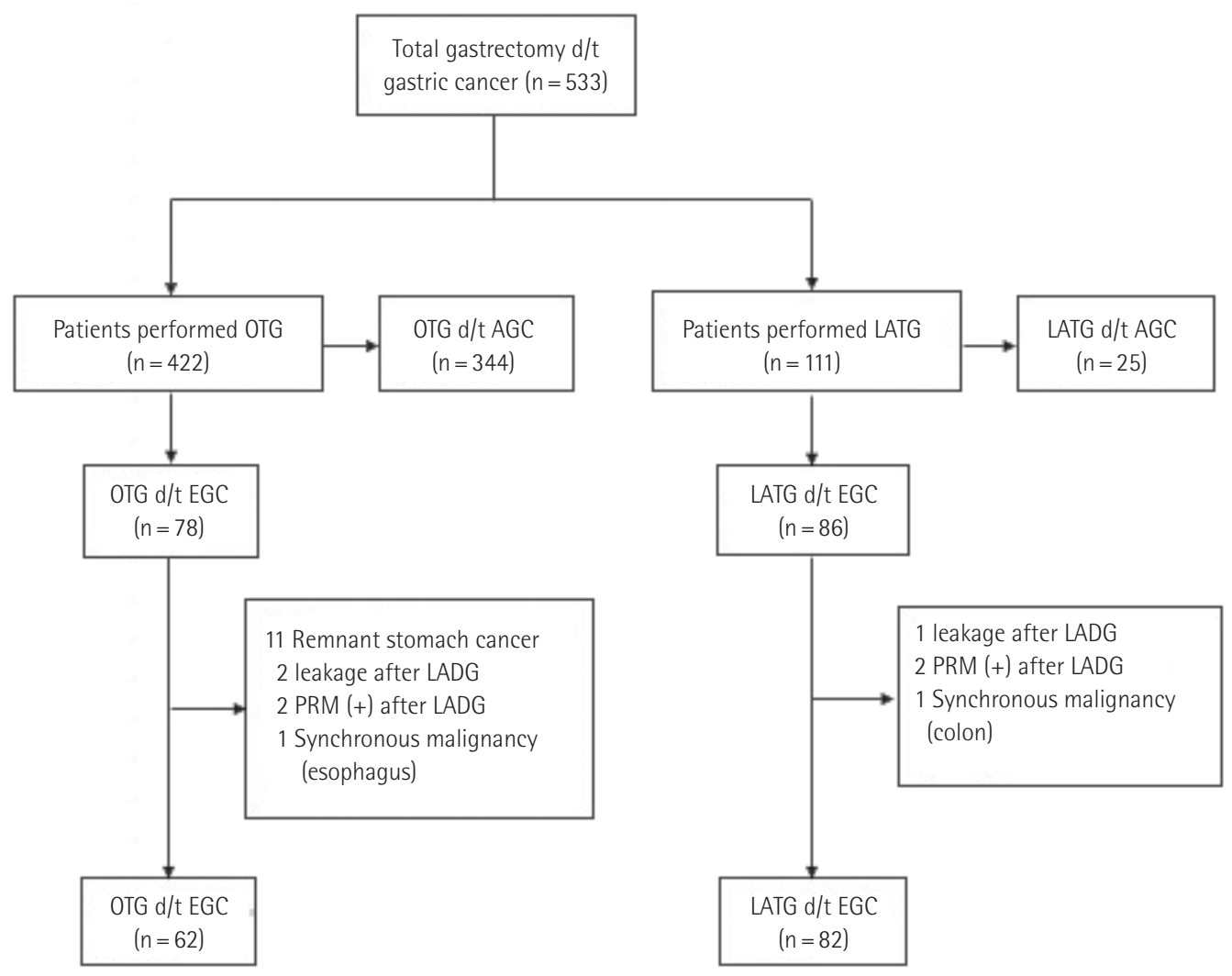

Fig. 1. Study flow chart. d/t, due to; OTG, open total gastrectomy; AGC, advanced gastric cancer; LATG, laparoscopic-assisted total gastrectomy; PRM, proximal resection margin; EGC, early gastric cancer. 
December 2010. Since then, side to side anastomosis has been performed but occasionally end to side anastomosis has been performed according to the patient. During the study period, 15 cases of end to side anastomosis and 67 cases of side to side anastomosis were performed respectively. End to side anastomosis with jejunojejunostomy was performed through the approximately $6-7 \mathrm{~cm}$ upper midline incision. Side to side anastomosis using overlap method was performed and then jejunojejunostomy was per-

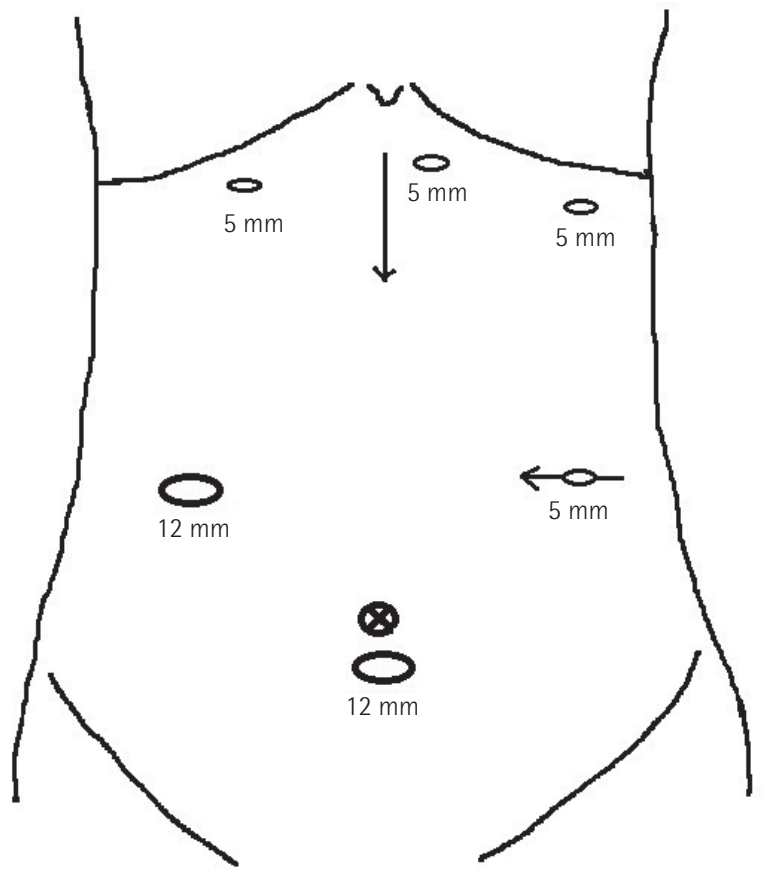

Fig. 2. Trocar placement for laparoscopic-assisted total gastrectomy. formed through 4-5 $\mathrm{cm}$ sized transverse incision using left lower trocar site.

To objectively assess the postoperative outcomes, we decided to apply the Clavien-Dindo classification [13]. This study was performed based on postoperative complications occurring within 30 days after TG. Grade I complications could not be assessed clearly because a retrospective study was performed. Based on our hospital data, grade II complications or higher were investigated. Grade III complications or higher were considered as major complications, a serious concern for many surgeons.

Statistical analyses were performed using SPSS ver. 12.0 (SPSS Inc., Chicago, IL, USA), and the variables are presented as mean \pm standard deviation. All results were computed as two tailed, and the level of statistical significance was set at P-value $<0.05$. We compared the baseline characteristics between patients who underwent OTG and LATG using chi-square test and independent $\mathrm{t}$-test. Independent $\mathrm{t}$-tests were used for mean comparisons of quantitative variables while chi-square tests for percentage comparisons of qualitative variables.

The present study was approved by the Institutional Review Board of the Gil Medical Center (IRB no. GBIRB2017-199).

\section{RESULTS}

The characteristics of the patient groups are shown in Table 1 . There is no statistically significant difference between the OTG and LATG groups according to age, body mass index, American Society of Anesthesiologists score, and previous abdominal surgery. Although we did not specially select patients according to sex,

Table 1. Characteristics of patients in the OTG and LATG groups

\begin{tabular}{|c|c|c|c|}
\hline \multirow{2}{*}{ Variable } & \multicolumn{2}{|c|}{ Operative method } & \multirow{2}{*}{ P-value } \\
\hline & OTG $(n=62)$ & LATG $(n=82)$ & \\
\hline Age (yr) & $60.60 \pm 11.24$ & $58.13 \pm 13.21$ & 0.240 \\
\hline Sex & & & 0.006 \\
\hline Male & $51(82.3)$ & $49(59.8)$ & \\
\hline Female & $11(17.7)$ & $33(40.2)$ & \\
\hline Body mass index & & & 0.857 \\
\hline$\leq 25 \mathrm{~kg} / \mathrm{m}^{2}$ & 43 (69.4) & $58(70.7)$ & \\
\hline$>25 \mathrm{~kg} / \mathrm{m}^{2}$ & $19(30.6)$ & $24(29.3)$ & \\
\hline ASA score & & & 0.665 \\
\hline I & $11(17.7)$ & $13(15.9)$ & \\
\hline$\|$ & $49(79.0)$ & $63(76.8)$ & \\
\hline III & $2(3.2)$ & $6(7.3)$ & \\
\hline Previous abdominal surgery history & & & 0.849 \\
\hline No & $46(74.2)$ & $62(75.6)$ & \\
\hline Yes & $16(25.8)$ & $20(24.4)$ & \\
\hline
\end{tabular}

Values are presented as mean \pm standard deviation or number $(\%)$.

OTG, open total gastrectomy; LATG, laparoscopy-assisted total gastrectomy; ASA, American Society Anesthesiologists. 
Table 2. Pathologic characteristics of the tumors in OTG and LATG patients

\begin{tabular}{|c|c|c|c|}
\hline \multirow{2}{*}{ Variable } & \multicolumn{2}{|c|}{ Operative method } & \multirow{2}{*}{ P-value } \\
\hline & OTG $(n=62)$ & LATG $(n=82)$ & \\
\hline Tumor size (cm) & $3.93 \pm 2.79$ & $3.39 \pm 2.20$ & 0.194 \\
\hline Tumor location & & & 0.058 \\
\hline Upper $1 / 3$ & $41(66.1)$ & $59(72.0)$ & \\
\hline Middle 1/3 & $10(16.1)$ & $19(23.2)$ & \\
\hline Lower $1 / 3$ & $2(3.2)$ & 0 & \\
\hline Others ${ }^{\mathrm{a})}$ & $9(14.5)$ & $4(4.9)$ & \\
\hline \multicolumn{4}{|l|}{ Margin distance $(\mathrm{cm})$} \\
\hline Proximal margin & $3.02 \pm 3.09$ & $2.93 \pm 2.65$ & 0.860 \\
\hline Distal margin & $12.73 \pm 5.10$ & $12.33 \pm 4.30$ & 0.606 \\
\hline Number of retrieved lymph nodes & $36.45 \pm 16.75$ & $34.62 \pm 14.59$ & 0.486 \\
\hline Depth of tumor invasion & & & 0.228 \\
\hline $\mathrm{T} 1 \mathrm{a}$ & $20(32.3)$ & $35(42.7)$ & \\
\hline $\mathrm{T} 1 \mathrm{~b}$ & $42(67.7)$ & $47(57.3)$ & \\
\hline Lymph node metastasis & & & 0.111 \\
\hline No & $56(90.3)$ & $73(89.0)$ & \\
\hline N1 & $2(3.2)$ & 8 (9.8) & \\
\hline N2 & $3(4.8)$ & $1(1.2)$ & \\
\hline N3a & $1(1.6)$ & 0 & \\
\hline Distant metastasis & & & $>0.99$ \\
\hline Mo & 62 (100.0) & $82(100.0)$ & \\
\hline M1 & 0 & 0 & \\
\hline TNM stage & & & 0.081 \\
\hline la & 56 (90.3) & 72 (87.8) & \\
\hline $\mathrm{lb}$ & 2 (3.2) & 9 (11.0) & \\
\hline Ila & $2(3.2)$ & $1(1.2)$ & \\
\hline $11 \mathrm{~b}$ & $2(3.2)$ & 0 & \\
\hline
\end{tabular}

Values are presented as mean \pm standard deviation or number (\%).

OTG, open total gastrectomy; LATG, laparoscopy-assisted total gastrectomy; TNM, tumor node metastasis.

${ }^{\text {a) } M u l t i p l e ~ g a s t r i c ~ c a n c e r ~ l e s i o n . ~}$

Table 3. Postoperative outcomes of OTG and LATG patients

\begin{tabular}{lccc}
\hline \multirow{2}{*}{ Variable } & \multicolumn{2}{c}{ Operative method } & P-value \\
\cline { 2 - 3 } & OTG $(\mathrm{n}=62)$ & LATG $(\mathrm{n}=82)$ & $<0.001$ \\
\hline Operating time (min) & $273.31 \pm 59.64$ & $237.61 \pm 57.66$ & 0.001 \\
Time to first intake of water (day) & $4.13 \pm 1.87$ & $2.85 \pm 2.38$ & 0.018 \\
Time to first flatus (day) & $3.74 \pm 1.83$ & $3.10 \pm 1.41$ & 0.832 \\
Time to remove first drainage (day) & $5.48 \pm 1.52$ & $5.41 \pm 2.19$ & 0.200 \\
Postoperative hospital day (day) & $11.31 \pm 6.38$ & $9.82 \pm 7.22$ & $>0.99$ \\
Intraoperative transfusion & & & $2(2.4)$ \\
$\quad$ Yes & $2(3.2)$ & $80(97.6)$ & $12(14.6)$ \\
$\quad 60(96.8)$ & $6(7.3)$ & $>0.99$ \\
No & $9(14.5)$ & & 0.731 \\
No. of overall complications & $3(4.8)$ & & \\
\hline
\end{tabular}

Values are presented as mean \pm standard deviation or number (\%).

OTG, open total gastrectomy; LATG, laparoscopy-assisted total gastrectomy.

LATG was performed more frequently in female patients than OTG $(\mathrm{P}<0.01)$.

Pathological characteristics of patients who underwent OTG and LATG are described in Table 2. There is no significant difference between the OTG and LATG groups in terms of tumor location and size, margin distance, TNM stage, and number of re- 
Table 4. Postoperative complications after OTG and LATG according to Clavien-Dindo classification

\begin{tabular}{|c|c|c|c|}
\hline Variables & OTG $(n=62)$ & LATG $(n=82)$ & P-value \\
\hline Grade of complications (C-D classification) & & & 0.942 \\
\hline$\|$ & $6(9.7)$ & $6(7.3)$ & \\
\hline Illa & $2(3.2)$ & $4(4.9)$ & \\
\hline$\| l l b$ & $1(1.6)$ & $2(2.4)$ & \\
\hline $\mathrm{Na}$ & 0 & 0 & \\
\hline $\mathrm{IVb}$ & 0 & 0 & \\
\hline V & 0 & 0 & \\
\hline Major complication (grade $\geq$ IIla) & & & 0.067 \\
\hline Anastomotic leakage & 0 & $3(3.7)$ & \\
\hline Anastomotic stenosis & $2(3.2)$ & 0 & \\
\hline Internal herniation & $1(1.6)$ & 0 & \\
\hline Intra-abdominal fluid collection & 0 & $2(2.4)$ & \\
\hline Pleural effusion & 0 & $1(1.2)$ & \\
\hline Minor complication (grade $<$ IIla) & & & 0.251 \\
\hline lleus & $4(6.5)$ & $1(1.2)$ & \\
\hline Pneumonia & $1(1.6)$ & $1(1.2)$ & \\
\hline Pancreatitis & 0 & $1(1.2)$ & \\
\hline Wound complication & 0 & $2(2.4)$ & \\
\hline Bleeding (intra-luminal) & $1(1.6)$ & 0 & \\
\hline Anastomosis leakage & 0 & $1(1.2)$ & \\
\hline
\end{tabular}

Values are presented as mean \pm standard deviation or number (\%).

OTG, open total gastrectomy; LATG, laparoscopy-assisted total gastrectomy; C-D, Clavien-Dindo.

Table 5. Comparison of early LATG and late LATG

\begin{tabular}{|c|c|c|c|}
\hline \multirow{2}{*}{ Operative method } & \multicolumn{2}{|c|}{ Operative method } & \multirow{2}{*}{ P-value } \\
\hline & Early LATG ${ }^{a}(n=41)$ & Late LATG $^{\text {b) }}(n=41)$ & \\
\hline No. of retrieved lymph nodes & $32.02 \pm 11.98$ & $37.22 \pm 16.54$ & 0.107 \\
\hline Type of anastomosis & & & 0.020 \\
\hline End to side & $12(29.3)$ & $3(7.3)$ & \\
\hline Side to side & $29(70.7)$ & $38(92.7)$ & \\
\hline Operating time (min) & $268.78 \pm 60.88$ & $206.44 \pm 32.15$ & $<0.001$ \\
\hline Time to first intake of water (day) & $3.24 \pm 3.27$ & $2.46 \pm 0.71$ & 0.139 \\
\hline Time to first flatus (day) & $3.24 \pm 1.53$ & $2.95 \pm 1.28$ & 0.351 \\
\hline Time to remove first drainage (day) & $5.73 \pm 2.75$ & $5.10 \pm 1.41$ & 0.192 \\
\hline Postoperative hospital day (day) & $10.73 \pm 9.85$ & $8.90 \pm 2.59$ & 0.256 \\
\hline Intraoperative transfusion & & & 0.494 \\
\hline Yes & 0 & $2(4.9)$ & \\
\hline No & $41(100.0)$ & $39(95.1)$ & \\
\hline No. of overall complications in LATG & $8(19.5)$ & $4(9.8)$ & 0.349 \\
\hline No. of major (grade $\geq$ IIla) complication in LATG & $6(14.0)$ & 0 & 0.026 \\
\hline Grade of complications (C-D classification) & & & 0.064 \\
\hline$\|$ & $2(4.9)$ & $4(9.8)$ & \\
\hline Illa & $4(9.8)$ & 0 & \\
\hline$\| l l b$ & $2(4.9)$ & 0 & \\
\hline $\mathrm{Na}$ & 0 & 0 & \\
\hline IVb & 0 & 0 & \\
\hline V & 0 & 0 & \\
\hline
\end{tabular}

Values are presented as mean \pm standard deviation or number $(\%)$. LATG, laparoscopy-assisted total gastrectomy; C-D, Clavien-Dindo. a) LATG performed from 2010 to 2013. ${ }^{\text {b) } L A T G ~ p e r f o r m e d ~ f r o m ~} 2014$ to 2016. 
trieved lymph nodes.

Postoperative outcomes are presented in Table 3. The median operating time was significantly longer in the OTG group (273.31 \pm 59.64 minutes) than in the LATG group $(237.61 \pm 57.66 \mathrm{~min}-$ utes; $\mathrm{P}<0.01)$. Time to first fluid intake was significantly shorter in the LATG group $(2.85 \pm 2.38$ days) than in the OTG group ( $4.13 \pm$ 1.87 days; $\mathrm{P}<0.001$ ). However, it should be considered that the first fluid intake began after esophagography at postoperative day 7 in the OTG group. Time to first flatus was significantly shorter in the LATG group ( $3.10 \pm 1.41$ days) than in the OTG group ( $3.74 \pm$ 1.83 days; $\mathrm{P}=0.018)$. There was no statistically significant difference between the two groups with regard to intraoperative transfusion $(\mathrm{P}>0.99)$, overall postoperative complications $(\mathrm{P}>0.99)$, and major postoperative complications $(\mathrm{P}=0.731)$.

Table 4 shows the grade and type of complications according to the Clavien-Dindo classification in the two groups. Although there is no significant difference on the pattern of major complications $(\mathrm{P}=0.067)$, leakage of esophagojejunostomy was the most common complication after LATG. Four cases of anastomosis leakage occurred in the LATG group. Three major anastomosis leakage was treated by percutaneous drainage or re-operation. One minor anastomosis leakage was treated with NPO and antibiotics without intervention.

Table 5 presents a list of postoperative outcomes of early and late LATG. Clinicopathological features were not significantly different between the two groups (data not shown). However, there is a significant difference in the type of anastomosis $(\mathrm{P}=0.02)$. The median operating time were significantly longer in the early LATG group than in the late LATG group $(268.78 \pm 60.88$ vs. $206.44 \pm$ $32.15 \mathrm{~mL} ; \mathrm{P}<0.01$ ). There is no statistically significant difference in the number of overall postoperative complications between the early LATG and late LATG groups $(\mathrm{P}=0.349)$. However, there is significant difference in the number of major complications between the two groups $(\mathrm{P}=0.026)$.

\section{DISCUSSION}

A successful LATG was first reported by Azagra et al. [14] in 1998. After an extensive experience with at least 300 cases of OTG and 200 cases of LADG, LATG was attempted in our hospital. Actually, most surgeons try LATG based on sufficient experience with OTG and LADG [15]. LATG was superior to OTG in terms of operating time, time to first flatus, and time to first fluid intake in our study. In other studies, the operating time in the LATG group had no significant difference or was significant longer than that in the OTG group $[9,16]$. However, the operating time required for LATG was shorter than that for OTG in our study (237 vs. 273 minutes). We thought that it was possible because one surgeon had enough time to learn OTG and LADG in a chronological order. The median numbers of retrieved lymph nodes were 36.45 and 34.62 in the OTG and LATG group, respectively. The proportion of N0 were 90.3\% for OTG and $89.0 \%$ for LATG. This means that D2 lymphadenectomy may be an extensive procedure. Recently, D1+ lymphadenectomy is being performed in patients diagnosed as EGC in our hospital. There was no significant difference in the resection margin status between the OTG and LATG groups. The number of retrieved lymph node and distance of proximal and distal resection margin were on the scale of oncological safety [17]. When LATG was performed by a skilled surgeon, the operating time could be similar to that in the OTG group as well as oncological safety acquired through experience.

The incidence of overall and major complications between the OTG and LATG groups was not statistically significant in the present study $(\mathrm{P}>0.99$ and 0.731$)$. However, four cases of anastomosis leakage occurred only in the LATG group. Two cases of these underwent revision of esophagojejunostomy. Lee et al. [18] reported a multicenter, retrospective study to compare the outcomes after LATG and OTG for EGC. The authors also concluded that anastomosis-related complications were the most frequent complications after LATG. To compare the incidence of postoperative complication by experience, the LATG group was divided into two phases. As a result, all anastomosis leakages occurred in the early LATG group, and this result was statistically significant $(\mathrm{P}=0.026)$. The major complication of LATG did not occur after 41 cases of LATG. Song et al. [19] and Jung et al. [15] reported that learning LATG required more than 50 and 100 cases, respectively, in which the variables were operating time and estimated blood loss. However, we thought that major complications after LATG could be a scale in the learning of the procedure.

In the late LATG phase, most of the esophagojejunostomies were performed using a linear stapler. Although Okabe et al. [20] reported that side-to-side anastomosis might reduce anastomosis-related complications, it is unclear whether this type of anastomosis affected a reduction of the major complications in the present study. Therefore, we believe that the standardization of anastomosis is necessary to lower the entry barrier in the performance of LATG. In our study, esophagojejunostomy in LATG was performed in two ways: end to side anastomosis and side to side anastomosis. $70.7 \%$ in early LATG group and $92.7 \%$ in late LATG group were performed side to side anastomosis using overlap method [21]. There is a significant difference in the proportion of anastomosis method between the early LATG group and late LATG group. However, all major complications were occurred in patients with side to side anastomosis in LATG and were limited to 
the early LATG phase. Major complication was not occurred in patients with end to side anastomosis in LATG. We thought this result could be evidence that postoperative outcomes of LATG were improved through a surgeon's experience.

LATG is not inferior to OTG and improved by learning in terms of postoperative outcomes in this study. However, it seems difficult to compare the long-term outcomes between patients undergoing LATG and those undergoing OTG for EGC in our study. To overcome this problem, a large number of the matched groups and a prospective randomized study are required.

\section{CONFLICT OF INTEREST}

No potential conflict of interest relevant to this article was reported.

\section{REFERENCES}

1. National Cancer Information Center. Cancer incidence in Korea, 2014 [Internet]. Goyang (KR): National Cancer Information Center; [cited 2017 Dec 1]. Available from: https:/www.cancer.go.kr/ lay1/S1T639C643/contents.do.

2. Kang KJ, Lee JH. Characteristics of Gastric Cancer in Korea-with an Emphasis on the Increase of the Early Gastric Cancer (EGC). J Korean Med Assoc 2010;53:283-9.

3. Kitano S, Iso Y, Moriyama M, Sugimachi K. Laparoscopy-assisted Billroth I gastrectomy. Surg Laparosc Endosc 1994;4:146-8.

4. Kim HH, Hyung WJ, Cho GS, Kim MC, Han SU, Kim W, et al. Morbidity and mortality of laparoscopic gastrectomy versus open gastrectomy for gastric cancer: an interim report: a phase III multicenter, prospective, randomized Trial (KLASS Trial). Ann Surg 2010;251:417-20

5. Huscher CG, Mingoli A, Sgarzini G, Sansonetti A, Di Paola M, Recher A, et al. Laparoscopic versus open subtotal gastrectomy for distal gastric cancer: five-year results of a randomized prospective trial. Ann Surg 2005;241:232-7.

6. Hamabe A, Omori T, Tanaka K, Nishida T. Comparison of longterm results between laparoscopy-assisted gastrectomy and open gastrectomy with D2 lymph node dissection for advanced gastric cancer. Surg Endosc 2012;26:1702-9.

7. Lee SE, Ryu KW, Nam BH, Lee JH, Kim YW, Yu JS, et al. Technical feasibility and safety of laparoscopy-assisted total gastrectomy in gastric cancer: a comparative study with laparoscopy-assisted distal gastrectomy. J Surg Oncol 2009;100:392-5.

8. Kim DJ, Lee JH, Kim W. Comparison of the major postoperative complications between laparoscopic distal and total gastrectomies for gastric cancer using Clavien-Dindo classification. Surg Endosc
2015;29:3196-204.

9. Jeong O, Jung MR, Kim GY, Kim HS, Ryu SY, Park YK. Comparison of short-term surgical outcomes between laparoscopic and open total gastrectomy for gastric carcinoma: case-control study using propensity score matching method. J Am Coll Surg 2013; 216:184-91.

10. Lee MS, Lee JH, Park DJ, Lee HJ, Kim HH, Yang HK. Comparison of short- and long-term outcomes of laparoscopic-assisted total gastrectomy and open total gastrectomy in gastric cancer patients. Surg Endosc 2013;27:2598-605.

11. Kawamura H, Yokota R, Homma S, Kondo Y. Comparison of invasiveness between laparoscopy-assisted total gastrectomy and open total gastrectomy. World J Surg 2009;33:2389-95.

12. Bo T, Peiwu Y, Feng Q, Yongliang Z, Yan S, Yingxue H, et al. Laparoscopy-assisted vs. open total gastrectomy for advanced gastric cancer: long-term outcomes and technical aspects of a case-control study. J Gastrointest Surg 2013;17:1202-8.

13. Dindo D, Demartines N, Clavien PA. Classification of surgical complications: a new proposal with evaluation in a cohort of 6336 patients and results of a survey. Ann Surg 2004;240:205-13.

14. Azagra JS, Goergen M, De Simone P, Ibanez-Aguirre J. Minimally invasive surgery for gastric cancer. Surg Endosc 1999;13:351-7.

15. Jung DH, Son SY, Park YS, Shin DJ, Ahn HS, Ahn SH, et al. The learning curve associated with laparoscopic total gastrectomy. Gastric Cancer 2016;19:264-72.

16. Mochiki E, Toyomasu Y, Ogata K, Andoh H, Ohno T, Aihara R, et al. Laparoscopically assisted total gastrectomy with lymph node dissection for upper and middle gastric cancer. Surg Endosc 2008;22:1997-2002.

17. Lee SR, Kim HO, Son BH, Shin JH, Yoo CH. Laparoscopic-assisted total gastrectomy versus open total gastrectomy for upper and middle gastric cancer in short-term and long-term outcomes. Surg Laparosc Endosc Percutan Tech 2014;24:277-82.

18. Lee JH, Nam BH, Ryu KW, Ryu SY, Park YK, Kim S, et al. Comparison of outcomes after laparoscopy-assisted and open total gastrectomy for early gastric cancer. Br J Surg 2015;102:1500-5.

19. Song JH, Choi YY, An JY, Kim DW, Hyung WJ, Noh SH. Shortterm outcomes of laparoscopic total gastrectomy performed by a single surgeon experienced in open gastrectomy: review of initial experience. J Gastric Cancer 2015;15:159-66.

20. Okabe H, Obama K, Tsunoda S, Tanaka E, Sakai Y. Advantage of completely laparoscopic gastrectomy with linear stapled reconstruction: a long-term follow-up study. Ann Surg 2014;259:109-16.

21. Inaba K, Satoh S, Ishida Y, Taniguchi K, Isogaki J, Kanaya S, et al. Overlap method: novel intracorporeal esophagojejunostomy after laparoscopic total gastrectomy. J Am Coll Surg 2010;211:e25-9. 